\title{
EXISTE UM CURRÍCULO MUSEAL? \\ AS TEORIAS CURRICULARES NA COMPREENSÃO DA EDUCAÇÃO EM MUSEUS
}

\author{
IS THERE A MUSEAL CURRICULUM? \\ THE CURRICULAR THEORIES IN THE UNDERSTANDING OF MUSEUM EDUCATION
}

\section{¿EXISTE UN CURRÍCULO MUSEAL? \\ LAS TEORÍAS CURRICULARES EN LA COMPRENSIÓN DE LA EDUCACIÓN EN MUSEOS}

\section{Luciana Conrado Martins ${ }^{1}$}

\section{RESUMO}

O conceito de currículo é multifacetado e, no universo da educação escolar, tem uma longa trajetória de debates e teorizações. Sua compreensão é alvo de diferentes abordagens teóricas, mais técnicas, trazendo o currículo como prescrição de conteúdos, organização do tempo e espaços da educação ou abordagens mais críticas, enfatizando as escolhas sociais e políticas na construção curricular. A utilização do conceito de currículo para a compreensão de outros contextos educacionais, como os museus, não é consensual, mas vem sendo cada vez mais explorada. Este artigo tem como objetivo propor uma reflexão sobre a especificidade da educação museal a partir das teorias curriculares, enfatizando seu potencial não só para a compreensão dos elementos que compõem a educação em museus, como para o entendimento das escolhas efetuadas e das tensões existentes na definição dos processos educacionais museais. Para isso, são trazidos autores do campo da educação em museus que utilizam as teorias curriculares, enfatizando os avanços e os limites das análises propostas. Como forma de superar os aspectos normativos e prescritivos dessas análises, é proposta a utilização das teorias críticas do currículo, em especial o conceito de dispositivo pedagógico de Basil Bernstein. Utilizando a estrutura teórica estabelecida por esse autor, são elucidados alguns aspectos da constituição e do funcionamento da educação nos museus, entendendo a prática educacional museal como currículo em processo.

PALAVRAS-CHAVE: Currículo. Educação. Museu. Teorias do currículo.

\begin{abstract}
The concept of curriculum is multifaceted and in the universe of school education has a long trajectory of debates and theorizations. Their understanding is subject to different theoretical approaches, more technical, bringing the curriculum as content prescription, time organization and spaces of education, or more critical approaches, emphasizing the social and political choices in curricular construction. The use of the concept of curriculum for the understanding of other educational contexts, such as museums, is not consensual, but has been increasingly explored. This article aims to propose a reflexion about the specificity of museum education by curricular theories, emphasizing its potential not only for the understanding of the elements that compose the museum education, but also for the understanding of the choices made and the tensions existing in the definition of educational museum processes. For this, authors of the field of museum education, that use the curricular theories, are brought, emphasizing the advances and limits of the proposed analyzes. As a way to overcome the normative and prescriptive aspects of these analyzes, it is proposed to use critical theories of the
\end{abstract}

\footnotetext{
${ }^{1}$ Doutora em Educação - Universidade de São Paulo (USP) - São Paulo, SP - Brasil. Coordenadora de projeto do PERCEBE - Pesquisa, Consultoria e Treinamento Educacional. São Paulo, SP - Brasil. E-mail:

lucianamartins@percebeeduca.com.br
}

Submetido em: 15/02/2018 - Aceito em: 05/06/2018

(C) ETD-Educação Temática Digital Campinas, SP $\quad$ v.20 $\quad$ n.3 $\quad$ p.640-661 jul./set. 2018


curriculum, especially the concept of pedagogical device of Basil Bernstein. Using the theoretical framework established by this author, some aspects of the constitution and functioning of museum education are elucidated, understanding the museum educational practice as a curriculum in process.

\section{RESUMEN}

El concepto de currículo es multifacético y en el universo de la educación escolar tiene una larga trayectoria de debates y teorizaciones. Su comprensión es objeto de diferentes enfoques teóricos, más técnicos, trayendo el currículo como prescripción de contenidos, organización del tiempo y espacios de la educación, o enfoques más críticos, enfatizando las elecciones sociales y políticas en la construcción curricular. La utilización del concepto de currículo para la comprensión de otros contextos educativos, como los museos, no es consensual, sino que se está explorando cada vez más. Este artículo tiene como objetivo proponer una reflexión sobre la especificidad de la educación museal a partir de las teorías curriculares, enfatizando su potencial no sólo para la comprensión de los elementos que componen la educación en museos, como para el entendimiento de las elecciones efectuadas y de las tensiones existentes en la definición de los procesos educativos museales. Para eso, se traen autores del campo de la educación en museos que utilizan las teorías curriculares, enfatizando los avances y límites de los análisis propuestos. Como forma de superar los aspectos normativos y prescriptivos de esos análisis, se propone la utilización de las teorías críticas del currículo, en especial el concepto de dispositivo pedagógico de Basil Bernstein. Utilizando la estructura teórica establecida por ese autor, se elucidan algunos aspectos de la constitución y del funcionamiento de la educación en los museos, entendiendo la práctica educativa museal como currículo en proceso.

PALAVRAS-CLAVE: Currículo. Educación. Museo. Teorías curriculares.

\section{INTRODUÇÃO}

Os estudos curriculares são um campo de investigação fértil e bem consolidado no universo da educação, abarcando desde as tradicionais prescrições curriculares até as discussões em torno de como o conhecimento é produzido, moldado e compartilhado por meio de processos educacionais (LOPES, MACEDO, 2002, 2011; SILVA, 1999, 2002). As múltiplas perspectivas presentes nas teorias curriculares disponibilizam, aos estudiosos interessados nas diferentes formas pelas quais o conhecimento é trabalhado nos ambientes educacionais, infinitas possibilidades de compreensão e discussão do tema. Nesse contexto de teorizações, vale ressaltar que os estudos curriculares são majoritariamente voltados para o universo escolar, dentro de uma compreensão do fazer educacional fortemente marcado pela educação formal. Raros são os estudos que se utilizam da diversidade das teorias curriculares para a compreensão de outros contextos educacionais para além do escolar formal ${ }^{2}$. Sendo assim, trazer o universo da educação museal para esse contexto de estudos não se faz sem polêmicas. Será que a categoria currículo, dentro da sua polissemia, pode ser

\footnotetext{
${ }^{2} \mathrm{O}$ surgimento dos estudos curriculares está fortemente marcado pela discussão sobre a seleção e a organização do que deve ser ensinado no ambiente escolar (LOPES, MACEDO, 2002). Mais recentemente, alguns aportes teóricos do campo curricular têm sido utilizados para compreender a constituição dos discursos museais (SOUZA, 2017; OLIVEIRA, 2010; MARANDINO, 2001), e mesmo das ações educativas que ocorrem nesses espaços, como será abordado nesta artigo.
}

(C) ETD-Educação Temática Digital Campinas, SP $\quad$ v.20 $\quad$ n.3 $\quad$ p.640-661 jul./set. 2018 
utilizada para a compreensão de processos educacionais que ocorrem em espaços culturais não formais, como museus, centros culturais e exposições?

Entender a educação museal a partir das teorias curriculares é um desafio - não só do ponto de vista educacional, como também dentro do próprio universo museal, no qual a educação não é aceita indiscriminadamente como um processo intrínseco a essas instituições (VALENTE, 2008; SEIBEL-MACHADO, 2009). O entendimento do museu como espaço de educação vincula sua relevância social contemporânea a sua capacidade de educar seus públicos (HOOPER-GREENHILL, 1994) e concorre diretamente com a visão dos museus como espaços prioritariamente dedicados à guarda, à pesquisa e à proteção de acervos. Uma teorização advinda do campo educacional, como proposto no presente artigo, parte de um olhar que vê, nessas instituições, processos de recontextualização do conhecimento especializado, oriundos da pesquisa sobre os acervos, e chega à produção do conhecimento educacional, com destaque para o papel dos agentes envolvidos, em especial, os educadores de museus (MARTINS, 2015). Nesse sentido, as teorias curriculares se revelam um campo extremamente fértil, na medida em que:

\begin{abstract}
As teorias curriculares, um subcampo dos estudos curriculares, são um campo interdisciplinar da educação que estuda o por que, qual e como o conhecimento é produzido, formatado e compartilhado. Os teóricos do currículo olham para uma série de disciplinas, incluindo os estudos culturais, a filosofia da educação, a psicanálise, a teoria literária, a ética, a antropologia, a sociologia e os estudos de gênero (ROSE, 2006, p.75, tradução nossa).
\end{abstract}

Por estarem na intersecção de diferentes campos do conhecimento, mas, ainda assim, ancoradas na educação, as teorias curriculares trazem a possibilidade de olhares múltiplos sobre os processos educacionais museais. Nesse contexto, a teoria de Bernstein, amplamente utilizada como suporte para estudos de currículo, permite a análise dos processos constitutivos do discurso pedagógico do museu. Vale apontar que este artigo é parte de um estudo mais amplo que busca estabelecer a especificidade do funcionamento e das características da educação museal (MARTINS, 2011). Nesse sentido, outros aspectos da constituição do currículo da educação museal, baseados na teoria de Bernstein, já foram abordados de forma mais aprofundada, como a conformação do campo recontextualizador oficial da educação em museus, os processos de conformação do discurso instrucional específico dos museus (MARTINS, 2015) e os processos de recontextualização pedagógica do museu $^{3}$.

\footnotetext{
${ }^{3}$ A conformação do currículo dos museus passa por agentes e agências recontextualizadoras, oficiais e pedagógicas, responsáveis pela transformação ideológica dos textos educacionais. O aprofundamento dessa discussão pode ser verificado em Martins e Marandino (2013).
}

(C) ETD- Educação Temática Digital Campinas, SP $\quad$ v.20 $\quad$ n.3 $\quad$ p.640-661 jul./set. 2018


Partindo dessa possibilidade de expansão das fronteiras de conhecimento sobre a educação em museus, optou-se, neste artigo, por uma reflexão teórica sobre a especificidade da educação museal a partir das teorias curriculares, com especial ênfase no conceito de dispositivo pedagógico de Basil Bernstein (1996, 1998). Para isso, primeiramente são discutidas análises sobre a educação em museus baseadas em teorias curriculares, de forma a evidenciar como os autores da educação museal têm trabalhado o tema.

No segundo momento, são apresentados os resultados de um estudo comparativo entre três tipologias institucionais de museus - um museu de artes plásticas, a Pinacoteca do Estado de São Paulo (PINA); um museu de ciências humanas, o Museu de Arqueologia e Etnologia da Universidade de São Paulo (MAE-USP); e um museu de ciência e tecnologia, o Museu de Astronomia e Ciências Afins (MAST) - analisados a partir da teoria de Bernstein.

Salienta-se que esses museus foram escolhidos justamente pela importância adquirida pela educação em seu interior. São instituições nas quais as ações educativas, bem estruturadas por um período de mais de cinco anos, se constituem como referência para a área de educação em museus nacionais. Ao mesmo tempo, os "casos exemplares", depreendidos a partir de uma metodologia qualitativa de estudos em educação, trazem à luz os caminhos institucionais percorridos pelos profissionais da área na estruturação do setor educativo dos museus. Considera-se que esses caminhos, à parte as singularidades contextuais de cada situação, são parte da especificidade da constituição do currículo da educação em museus.

Os dados para este artigo foram coletados ao longo dos anos de 2009 e 2010, por meio de entrevistas com os educadores dos museus estudados. Além disso foram coletados e analisados documentos institucionais produzidos pelos museus. Os referenciais da pesquisa qualitativa em educação (BOGDAN e BIKLEN, 1994; COHEN et al., 2007) foram utilizados como subsídio metodológico para a coleta de dados e estruturação da pesquisa, visando a compreensão dos processos educacionais em jogo no ambiente museal, bem como para a identificação dos agentes que deles participam, como forma de delimitar e compreender o currículo da educação museal.

\section{AS TEORIAS CURRICULARES NA COMPREENSÃO DA EDUCAÇÃO MUSEAL}

O uso das teorias curriculares para a compreensão da educação museal ainda é incipiente e praticamente restrito a reduzido número de autores anglo-saxões especialmente norte-americanos. Muitas das referências encontradas têm como objetivo o aprimoramento dos processos educativos dos museus, dentro de uma tendência prescritiva, 
aliada aos primeiros teóricos dos estudos curriculares ${ }^{4}$. As discussões empreendidas voltamse para a identificação dos elementos que moldam as práticas educacionais nos museus.

Esse é o caso de Elizabeth Vallance $(1995,2004,2006)$, cuja pesquisa tem utilizado modelos teóricos de currículo para descrever os propósitos dos programas de museus e avaliar seus resultados. Vallance parte da afirmação da existência de um "currículo público" em todos os recursos informativos existentes fora da escola: periódicos impressos, televisão e, obviamente, os museus. Para ela, o que justifica o "público", utilizado em sua definição, é o fato de que o conhecimento disponibilizado no museu, e em outras fontes de informação fora da escola, é autosselecionável por aqueles que por esse conhecimento se interessem, tornando-o mais disponível e maleável do que as formas educativas tradicionais. A partir dessa caracterização inicial, Vallance busca desvendar os aspectos que compõem a educação em museus, e a estruturação do conhecimento por parte do visitante, visando o estabelecimento de um modelo ideal para a educação nesses espaços.

Vallance propõe ainda uma reflexão a partir do modelo dos cinco princípios de Huebner (2004, p.348), que, no seu entender, é “(...) melhor fundamentado e menos distorcido modelo curricular aplicável à educação em museus". Para Vallance, os cinco princípios de Huebner, que ela prefere denominar "qualidades do meio ambiente de aprendizagem", podem ser amplamente encontrados nos museus. Esse é o caso das qualidades política e ética, fortemente presentes em inúmeras exposições e ações de museus, notadamente naquelas voltadas à inserção dos não públicos nessas instituições. A dimensão técnica, por sua vez, tem sua perspectiva ampliada dentro do museu na medida em que não é estruturada a partir de testes mensuráveis com o público e sim a partir da percepção da equipe do museu acerca do sucesso, ou não, dos programas propostos. Já a dimensão científica tem se mostrado cada vez mais robusta, com o desenvolvimento, em anos recentes, de pesquisas acerca de como os visitantes aprendem dentro dos museus. Por fim, é a qualidade estética a mais valorizada, por Vallance, como característica do universo dos museus, na medida em que, para a autora, essa é uma perspectiva intrinsecamente presente em toda a ação museal.

Vallance também propõe uma segunda perspectiva de compreensão e prescrição para a educação em museus, denominada de "modelo narrativo" (storyline model). Baseado nos conceitos advindos das teorias de aprendizado sociocultural, esse modelo não é, de acordo com a autora, estruturado a partir de uma proposta de currículo escolar e sim na ideia de "conexões com as histórias que os visitantes criam em suas experiências e que mais tarde se refletem em suas visitas aos museus" (VALLANCE, 2004, p.352, tradução nossa). A partir de

\footnotetext{
${ }^{4}$ Esses primeiros teóricos estão, em sua maior parte, associados com as chamadas tendências pedagógicas tradicionais (LIBÂNEO, 1990).
}

(C) ETD-Educação Temática Digital Campinas, SP $\quad$ v.20 n.3 $\quad$ p.640-661 jul./set. 2018


pesquisas que exploram o caráter narrativo das conexões de aprendizado estabelecidas pelos visitantes antes, durante e depois de suas passagens pelos museus, Vallance propõe um currículo de museu visto como uma história criada pelos educadores e experimentada de maneiras diferentes por cada visitante.

Esse modelo pretende "capturar a natureza do aprendizado dos museus", dando ênfase ao papel decisivo do público nos processos educacionais dessas instituições. Na visão de Vallance, as teorias curriculares são uma ferramenta valiosa para que as histórias contadas pelos museus engajem os visitantes e produzam avaliações que tornem as narrativas cada vez melhores, ao mesmo tempo em que oferecem um vocabulário e uma sintaxe que sirvam para guiar e avaliar esse processo.

As reflexões de Vallance acerca da utilidade das teorias curriculares, como forma de compreender a natureza das práticas educativas nos museus, encontram paralelo em outros autores da área, tais como Soren (1992) e Beer e Marsh (1988). Esses autores buscam compreender as características da educação em museu, em especial a forma como o conhecimento educacional é moldado e partilhado nessas instituições, utilizando, para isso, teorias curriculares consagradas no campo da educação.

No caso de Barbara Soren, o foco está no desenvolvimento de estratégias para a produção de currículos no museu. Para essa autora, o currículo de um museu deve voltar-se ao esclarecimento aos visitantes dos aspectos particulares da instituição. Para isso, a autora propõe a utilização da teoria curricular de Schwab na análise da produção de uma exposição temporária, na Art Gallery of Ontario, intitulada "Pontos de vista: aproximações à arte contemporânea" 5 .

Para Soren, a educação nos museus está relacionada à "experiência de visita pessoalmente significativa" ou Edutainment ${ }^{6}$. Esse tipo de visita relaciona aspectos de lazer com aprendizado, levando o público a escolher livremente locais com essas características em detrimento de outros. Essa conclusão é corroborada pela avaliação do comportamento dos visitantes em "Pontos de Vista". Na primeira fase da exposição, de caráter mais tradicional", os visitantes faziam um percurso rápido, prestando pouca atenção às obras expostas. Ou seja, sem a presença de uma abordagem educacional - que Schwab denomina ensinar - é difícil para

\footnotetext{
5 Schwab $(1973,1983)$ desenvolveu a teoria dos quatro lugares comuns, que compreendem: "assunto", "professor", "estudantes" e "meio".

${ }^{6}$ Essa palavra é fruto da junção de education (educação) com entertainment (entretenimento, lazer).

${ }^{7}$ Para melhor avaliar as reações do público, os educadores da exposição dividiram os trabalhos em duas fases: uma, mais tradicional, acompanhada somente de etiquetas sucintas e outra, mais interativa, com uso de ferramentas interpretativas, em suportes variados, com intuito de estender o tempo de permanência do visitante e ajudá-lo a pensar em alguns aspectos, selecionados pelos educadores, das obras de arte.
}

(C) ETD- Educação Temática Digital Campinas, SP $\quad$ v.20 $\quad$ n.3 $\quad$ p.640-661 jul./set. 2018


o visitante, sem experiência com trabalhos artísticos, ser esclarecido sobre o assunto da exposição e, consequentemente aprender sobre seus conteúdos.

Outro aspecto importante, mencionado pela autora em sua análise do processo de produção curricular de "Pontos de Vista", diz respeito ao papel dos educadores, frente aos outros membros da equipe do museu, durante as tomadas de decisão. Curadores e pesquisadores, responsáveis pelos conteúdos da exposição, criticaram o que consideravam um uso excessivo de "facilitadores" na segunda fase da exposição, tidos como simplistas e, em alguma medida, competindo com as obras.

A análise de Soren parte da premissa de que o museu é uma instituição curricular cabendo, portanto, elaborar uma reflexão sobre como o seu currículo é construído. Como, segundo essa autora, o currículo do museu é estruturado a partir da exposição, sua análise toma um rumo diferenciado da análise de Vallance. Para Vallance, o currículo engloba a exposição (e as ações educativas realizadas) com o intuito de torná-la palatável. Também, diferentemente de Vallance, Soren faz uma análise não prescritiva, não buscando implementar um modelo ideal para a estruturação da educação em museus e sim objetivando estabelecer um modelo analítico para a compreensão desses processos de construção de sentidos pelos visitantes.

A contribuição de Soren para o entendimento da educação praticada nos museus é, nesse sentido, semelhante à de Beer e Marsh (1988), cuja reflexão tem como objetivo "contribuir para a conexão conceitual entre a educação escolar e a não escolar usando um modelo curricular escolar como impulso para o estudo do currículo em uma instituição educacional não escolar - o museu" (BEER e MARSH, 1998, p.223, tradução nossa). Sua justificativa é apresentada a partir da argumentação de que a educação não escolar deve ser parceira da educação escolar, necessitando para isso ser investigada, descrita e definida sistematicamente a partir de seus próprios elementos e relações.

Como sua premissa estava baseada na utilização de um modelo curricular escolar que pudesse trazer um tipo específico de contribuição conceitual, os autores optaram por um modelo curricular descritivo e não prescritivo. Dessa forma, foi selecionado o modelo proposto por Goodlad, Klein e Tye que, segundo Beer e Marsh, contém os elementos necessários à descrição de um currículo ${ }^{8}$.

\footnotetext{
${ }^{8}$ O modelo curricular de Goodlad, Klein e Tye (1979) é composto por nove elementos descritivos: metas e objetivos, materiais, conteúdos, atividades de aprendizagem, estratégias, avaliação agrupamento, tempo e espaço; cinco perspectivas: ideal, formal, instrucional, operacional e experimental; e dez fatores qualitativos: descrição, tomada de decisão, princípios, prioridades, atitudes, apropriação, abrangência, individualização, barreiras e facilitadores.
}

(C) ETD-Educação Temática Digital Campinas, SP $\quad$ v.20 $\quad$ n.3 $\quad$ p.640-661 jul./set. 2018


Os aspectos levantados levam os autores a duas conclusões: a primeira, de que nos museus o público não é essencial, já que grande parte das percepções dos visitantes é diferente da percepção da equipe do museu $^{9}$. A segunda conclusão aponta para a complexidade do que eles denominam "currículo dos museus", na medida em que o modelo proposto por Goodlad, Klein e Tye parece não dar conta de descrever as relações entre os diversos elementos presentes nesse "currículo".

Como forma de solucionar essas questões, Beer e Marsh propõem um modelo curricular, adaptado do modelo inicialmente escolhido, na intenção de chegar a um "dispositivo heurístico" que permita a descrição de diferentes configurações curriculares: museais ou escolares. Os elementos descritivos, oriundos do modelo original com pequenas modificações, foram agrupados formando um novo modelo que permite a descrição de diferentes configurações curriculares a partir de três variáveis: as relações entre os elementos; a influência relativa de cada elemento; e se os elementos estão sob o controle da instituição ou de seu público ${ }^{10}$.

A partir do modelo proposto, os autores chegam a uma descrição curricular dos museus em termos bastante sucintos. As variáveis "materiais" e "conteúdos" são as que possuem maior influência no currículo dos museus, juntamente com "espaço". Muitas vezes, essas três variáveis não podem ser percebidas separadamente e ambas têm grande importância, tanto para a equipe como para o público. Já as variáveis "atividades" e "estratégias de apresentação" não são tão próximas, evidenciando que nem sempre a equipe consegue prever quais atividades serão realizadas pelo público na exposição com o objetivo de adquirir conhecimento ${ }^{11}$. A variável "tempo", por sua vez, aparece estreitamente relacionada com "atividade", com forte ênfase sobre os visitantes. As variáveis "metas", "agrupamento" e "avaliação" têm pouca influência no currículo do museu, sendo que "agrupamento" está sob o controle dos visitantes. Por fim, a variável "objetivos" 12 não aparece no currículo do museu.

A vantagem da proposição, de acordo com os autores, reside no fato de ser um modelo flexível, possibilitando comparações de distintos arranjos curriculares. O modelo

\footnotetext{
${ }^{9}$ Para os autores, isso se deve ao fato de que muitas das exposições de museus são feitas para impressionar especialistas, doadores ou outros profissionais de museus, em detrimento do público visitante.

${ }^{10}$ Os elementos descritivos do modelo adaptado de Beer e Marsh são: metas, objetivos, materiais, conteúdo, atividades, estratégias de apresentação, avaliação, agrupamento, tempo e espaço.

${ }^{11}$ No modelo de Beer e Marsh, "atividades" se refere a "experiências que resultam em conhecimento ganho" e "estratégias de apresentação" a "seleção e arranjo de outros elementos que resultam em conhecimento ganho" (BEER e MARSH, 1998, p. 235, tradução nossa).

${ }^{12}$ Existe uma diferença entre metas e objetivos no modelo dos autores. "Metas" são "os resultados gerais que a instituição e seu público esperam conseguir" e "objetivos" são "os resultados de aprendizagem específicos esperados pela instituição, seu público, ou ambos" (BEER e MARSH, 1998, p. 235, tradução nossa).
}

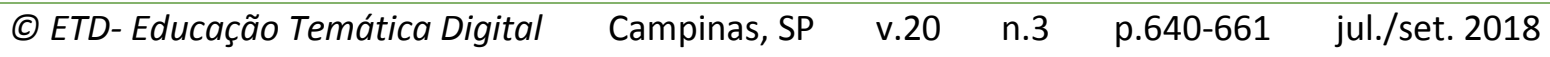


também seria vantajoso por permitir que “(...) vários currículos possam ser descritos de acordo com suas próprias características, sem referência ao currículo das escolas" (BEER e MARSH, 1998, p. 239, tradução nossa), contribuindo, em última instância, para a integração dos diversos contextos educacionais em um paradigma de educação para todos.

A partir dos autores aqui expostos, é possível perceber que a área de estudos de currículo traz contribuições efetivas para a compreensão da constituição e do funcionamento da educação museal. Por meio das teorias curriculares, podem ser delimitados os elementos que fazem parte dessa modalidade educacional. Nesse sentido, suas análises trazem aspectos importantes para a percepção de como essa educação se constitui: tempo, espaço, objetos/conhecimentos e educadores têm características próprias na educação praticada nos museus, diferenciadas de outras modalidades educacionais.

Essas constatações, entretanto, não exploram os aspectos processuais dessa educação, ou seja, não é possível compreender por que a educação em museus é da forma que os teóricos dessa área afirmam ser. Os mecanismos que regem a seleção e a distribuição do conhecimento na educação museal, bem como a motivação de seus agentes, permanecem ocultos. A aposta deste trabalho centra-se, portanto, na hipótese de que a especificidade da educação em museus reside justamente nesse processo de constituição, no qual atuam diferentes forças.

Entender o porquê da escolha de determinadas ações educativas em detrimento de outras, ou da seleção de temas e conteúdos, é uma questão que se configura importante para a compreensão do currículo dos museus. Cabe dizer que as produções do denominado campo do currículo voltam-se para teorias e temáticas bastante diversas (LOPES, MACEDO, 2002; 2011). Para os propósitos do presente texto, interessa entender os processos de criação e seleção responsáveis pela estruturação do currículo dos museus. Nesse sentido, a teoria do funcionamento do dispositivo pedagógico, proposta por Basil Bernstein (1996; 1998), é adequada ao oferecer a possibilidade de uma visão sistêmica sobre os mecanismos de constituição e funcionamento dos processos educacionais existentes nessas instituições. Ao destrinchar a gramática de elaboração e transmissão dos códigos sociolinguísticos por meio dos sistemas educacionais institucionalizados, o autor desenvolve um complexo teórico capaz de elucidar o funcionamento dos processos educacionais, evidenciando as relações de poder e controle aí presentes.

Por meio do conceito de dispositivo pedagógico, proposto por Bernstein, pretende-se iniciar uma discussão acerca dos "porquês" e dos "comos" da educação museal - debate que, apesar de amplamente presente nos estudos acerca do currículo escolar (APPLE, 1995, 2006; LOPES e MACEDO, 2002; MOREIRA e SILVA, 1995), ainda é bastante tímido nos estudos sobre educação em museus. Entende-se que essa categoria educacional não é alvo de estudos

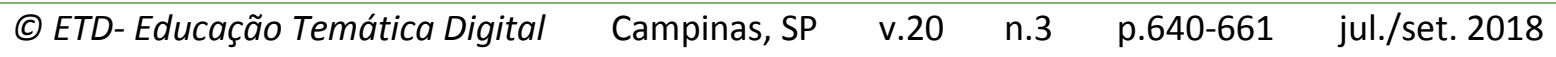


sistemáticos na área educacional e que, apesar da inegável contribuição dos processos educacionais museais para a educação dos cidadãos (ALLARD e LEFEBVRE, 1997; HEIN, 1998; HOOPER-GREENHILL, 1994; ROBERTS, 1997, entre muitos outros), eles ainda não se constituem como um campo de estudos específico (MARTINS, 2011). Este artigo tem como objetivo justamente contribuir para esse processo de compreensão e delimitação da especificidade dessa tipologia educacional denominada educação em museus. O conceito de dispositivo pedagógico se adequa a essa missão na medida em que estabelece princípios descritivos para os processos educacionais, possibilitando a descrição das práticas de organização, das práticas discursivas e das práticas de transmissão inerentes a qualquer tipo de ação pedagógica, inclusive dos museus. Considera-se esse um passo essencial para a inserção da temática da educação museal na área educacional de forma mais ampla.

\section{FUNCIONAMENTO DO DISPOSITIVO PEDAGÓGICO MUSEAL: ASPECTOS DA RELAÇÃO ENTRE OS EDUCADORES DE MUSEUS E SEUS PÚBLICOS}

O conceito de dispositivo pedagógico foi cunhado por Basil Bernstein $(1996,1998)$ para a compreensão das relações de poder e dos princípios de controle atuantes entre os diversos agentes que participam do processo de transformação e aquisição do conhecimento no âmbito educacional. Na acepção desse autor, a comunicação pedagógica é regulada por esse dispositivo, que atua na produção, na reprodução e na transmissão culturais dentro da esfera educacional, a partir de parâmetros próprios de funcionamento. Esses parâmetros variam segundo o contexto, mas são relativamente estáveis em sua estrutura intrínseca. Assim como no caso do dispositivo linguístico, as regras de funcionamento do dispositivo pedagógico também sofrem influências ideológicas diversas, podendo, assim, gerar uma imensa variedade de resultados comunicativos distintos. Entretanto, diferentemente do dispositivo linguístico, o dispositivo pedagógico traz em si o potencial de subversão, oriundo das próprias formas de comunicação por ele geradas (ILLERA, 1995).

É importante contextualizar que as preocupações teóricas de Bernstein estão inseridas em um movimento intelectual mais amplo de renovação temática, epistemológica e metodológica da pesquisa em educação, ocorrido a partir dos anos 1970 em países da

Europa e nos Estados Unidos ${ }^{13}$. De maneira geral, pode-se afirmar que, dentro dessa vertente, a educação é vista como portadora das relações de poder presentes na sociedade e as relações pedagógicas, seja entre pais e filhos, seja entre professores e alunos, são entendidas como condutoras de padrões de dominação sociais historicamente constituídos, em um

\footnotetext{
${ }^{13}$ Identificado conceitualmente com as chamadas teorias da reprodução, o conjunto de trabalhos surgidos sob essa influência veio a ser conhecido como "teorias críticas da educação" e suas pesquisas centram-se na compreensão e na revelação dos mecanismos de construção - sociais, históricos e econômicos - que condicionam a educação e o currículo escolar (FORQUIN, 1989).
(C) ETD-Educação Temática Digital
Campinas, SP
v. 20
n.3
p.640-661
jul./set. 2018 
processo de reprodução das desigualdades sociais. Bernstein, nesse contexto, voltou seu olhar para a compreensão do posicionamento do indivíduo na sociedade e suas possibilidades de comunicação dentro da esfera pedagógica legítima. Seu objetivo, diferentemente dos demais teóricos reprodutivistas, era a proposição de um modelo capaz de descrever as regras subjacentes à configuração da forma especializada de relação social que é realizada pelo dispositivo pedagógico ${ }^{14}$. Sua reflexão parte do pressuposto de que a relação pedagógica está presente em qualquer tipo de relação social que, envolvendo a comunicação de conteúdos específicos, subentenda a existência de uma hierarquização entre os sujeitos dela participantes.

Segundo Bernstein, o papel do dispositivo pedagógico é regular a comunicação pedagógica. Dessa forma, a seleção da cultura que se processo no interior do sistema educacional, e que tem um papel na especialização dos comportamentos e da consciência dos sujeitos, é regulada pelo dispositivo pedagógico segundo suas regras internas de funcionamento ${ }^{15}$. Ou seja, "entre o poder e o conhecimento e entre o conhecimento e as formas de consciência está sempre o aparelho pedagógico que, através das regras que o constituem, controla essas relações e, assim, garante a especialização das formas de consciência" (DOMINGOS et al, 1986, p. 286). O conteúdo pedagogizado, dessa forma, é submetido às regras do dispositivo, limitando as possibilidades dos significados transmitidos. Para esse autor o processo pedagógico que acontece no interior das instituições educacionais, tem um papel fundamental na reinterpretação dos saberes sociais para fins educacionais e de ensino. Pode-se afirmar, assim, a existência de um conhecimento institucional específico e de uma dimensão sociológica particular, que conforma o discurso pedagógico dessas instituições educacionais (LOPES, MACEDO, 2011).

Bernstein afirma que, no contexto de reprodução, ou seja, no contexto da relação entre educadores e educandos, o discurso pedagógico é perpassado por uma dimensão temporal e uma dimensão espacial. A matriz temporal regula as relações de aquisição e transmissão e a matriz espacial regula as relações entre e dentro dos diferentes locais de reprodução. Essas duas matrizes - espacial e temporal - são, por sua vez, determinadas pela

\footnotetext{
${ }^{14}$ Bernstein (1996) apontou que a lacuna dos teóricos reprodutivistas diz respeito aos princípios descritivos dos processos pedagógicos que perpetuam as desigualdades sociais. "Elas [as teorias reprodutivitas] estão preocupadas apenas em compreender como relações externas de poder são transportadas pelo sistema, elas não estão preocupadas com a descrição do transportador, apenas com um diagnóstico de sua patologia" ( $p$. 238, itálico do autor).

${ }^{15}$ Segundo o complexo teórico criado por Bernstein, o dispositivo pedagógico determina a especialização das consciências, sendo um dos ganhos de sua teorização a possibilidade da explicitação das relações entre macro e micro na esfera educacional (SADOVNIK, 1995). Ou seja, entre as relações de classe e os comportamentos dos sujeitos.
}

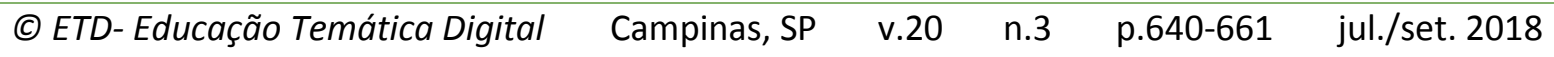


relação entre o discurso instrucional e o discurso regulador ${ }^{16}$. Sendo assim, é possível considerar a presença de três elementos na reprodução do discurso pedagógico: tempo, espaço e discurso (conceitual/instrucional e moral/regulador), que se interpenetram e se interrelacionam, estabelecendo as diferentes modalidades pedagógicas.

Para a compreensão da especificidade do funcionamento do nível da reprodução do dispositivo pedagógico do museu, a análise aqui empreendida centrou-se em um desses elementos constituintes: a matriz temporal.

A matriz temporal em Bernstein está configurada para além do mero tempo cronológico. O tempo do dispositivo pedagógico é, antes de tudo, um tempo institucional e constitui-se como fator determinante para a constituição das práticas instrucionais. Esse tempo relaciona-se com o discurso instrucional e, em menor medida, com o discurso regulador, estabelecendo a dinâmica das práticas de comunicação entre educandos e educadores, entre os próprios educadores e entre os educandos. Ou seja, ele regula, em última instância, o processo comunicacional da transmissão-aquisição pedagógica. É a concepção de tempo atuante nessa comunicação que, em última instância, regula a quantidade de momentos que o público estará envolvido em uma determinada atividade daquela instituição. Também é essa mesma concepção que determina as relações entre tempo, conteúdo e tipologia de sujeitos, conformando o ritmo possível de ação pedagógica. Ou seja, no nível da prática educativa, é uma determinada concepção de tempo que regula qual atividade será apropriada para que determinada tipologia de público aprenda determinados conteúdos. Nesse sentido, um primeiro aspecto que emerge, de forma contundente, da fala dos educadores é a efemeridade do tempo da experiência educativa museal.

No caso do museu, uma característica é o fato de promover encontros/visitas muito pontuais. A continuidade do contato com os públicos atendidos pelos educativos pode acontecer, mas não costuma ser a regra. Isso singulariza muito a experiência, porque os processos têm que acontecer muito rapidamente, num espaço muito curto de tempo. (PINA - educador 2)

Ninguém te garante que aquele aluno vai voltar ao museu; talvez você nem lembre dele. Então, nós temos que atuar, numa qualidade especial, naquela uma hora e meia que você tem que fazer uma coisa com começo, meio e fim e que toque as pessoas de uma maneira especial. (MAE - educador 1)

Essa efemeridade traz especificidades na regulação do discurso pedagógico a ser reproduzido. Os públicos, denominados dentro da teoria de Bernstein de "adquirentes", têm

\footnotetext{
${ }^{16} \mathrm{O}$ discurso instrucional diz respeito ao conteúdo de destrezas técnicas oriundas do discurso original. É o discurso da competência, que transmite competências e suas relações mútuas. Já o discurso regulador é aquele que cria as regras de comportamento e ordem social embutidas no discurso pedagógico. 0 discurso regulador tem a primazia sobre o discurso instrucional: é ele que define as regras de funcionamento que conformarão o discurso técnico original à lógica da relação pedagógica.
}

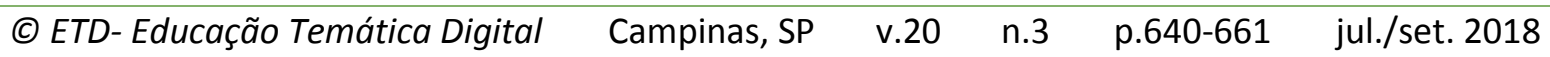


um domínio muito mais efetivo sobre o seu tempo e sobre o tipo de experiência que será estabelecida nesse período de visitação.

Eu trabalho meses numa exposição, o público tem duas horas na exposição, ou quatro se ele voltar. Então o educador tem que, na verdade, refazer muito do seu próprio processo, na relação com o objeto, mas de uma forma estruturada, de forma que você permita que o público, num espaço menor de tempo, tenha o mínimo daquela experiência de aprendizagem. (MAE - educador 1)

De acordo com o depoimento, percebe-se que a lógica do trabalho educativo museal baseia-se no estabelecimento de uma "agenda" para o "tempo efêmero" da visita. Em última instância, o educador, ao propor atividades pedagógicas no âmbito museal, tenta estabelecer estratégias que permitam a apreensão de certos objetivos educacionais por ele desejados. É uma negociação entre o tempo do público e os propósitos educacionais museais - que sempre pressupõem algum grau de aprendizado e, portanto, de relação com os conteúdos expostos. Esse tipo de negociação fica especialmente claro no caso das visitas educativas, realizadas com público escolar e espontâneo nos museus estudados.

\begin{abstract}
A nossa visita dura 2 horas, em um dos módulos da exposição. Então, tem todo um trabalho, primeiro de preparação, de conversas, entender um pouco qual é a preparação do grupo, qual é a expectativa do grupo, como eles têm os conceitoschave que a exposição aborda, trabalhados ou não trabalhados. [...] E por isso que a gente faz a opção de trabalhar um módulo. Restringe um pouco, mas pelo menos é um módulo, que fazer isso na exposição inteira também todo mundo vai sair daqui morto. (MAE - educador 2)
\end{abstract}

A visita dura 1h30. Não é uma visita longa, é uma visita curta. Se é para público espontâneo que quer uma apresentação, ela ainda é menor, 1h15. Porque tem uma parte complexa, que aqui é necessário, que é como se comportar no museu, porque você não pode correr, gritar [...]. Então, tem uma parte que é uma apresentação institucional, uma conscientização, do que é o Museu, uma parte mais introdutória. Tem uma parte mais de apreciação de obra, leitura, contextualização, mais dialógicas. E tem uma parte de proposta poética, e o educador vai fazendo conforme a sua lógica de construção está acontecendo com aquele grupo. (PINA - educador 1).

A matriz temporal do museu atua, portanto, sobre a maneira como os conteúdos serão estabelecidos e para que tipo de público, em uma atividade educativa. Essa matriz, no caso dos museus estudados, se traduz em um tempo fragmentado, inserido dentro da lógica subjetiva dos interesses de cada visitante. É essa lógica subjetiva que vai, em última instância, definir a quantidade de tempo que cada visitante dedicará às ações educacionais. A regulação do visitante é, por sua vez, "negociada" com a temporalidade prevista pelos educadores para a duração de cada ação. Nesse sentido, um aspecto importante a ser considerado, para a compreensão do funcionamento da matriz temporal nos museus, são as tipologias de públicos atendidas pelos serviços educativos. A partir da pesquisa realizada, foi possível determinar que, para cada tipologia de público, existe uma ação educacional específica.

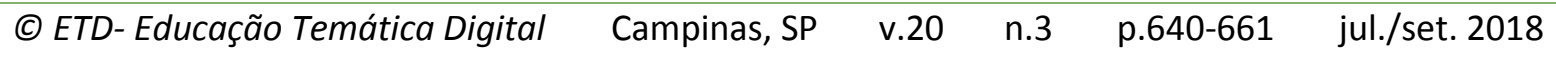


No caso dos museus estudados, constataram-se similitudes nas tipologias de público adotadas por cada instituição. No Museu de Astronomia e Ciências Afins, os públicos são, a princípio, separados entre "público escolar" e "público visitante". Na Pinacoteca do Estado de São Paulo, os documentos consultados revelam que o público é contabilizado de maneira geral, pela instituição, como "público visitante". Já, no caso do Museu de Arqueologia e Etnologia da USP, os públicos são categorizados em "visitantes" e "grupos escolares". O que se depreende dessa categorização é a singularização dos públicos escolares frente aos demais grupos frequentadores dos museus.

É importante perceber, entretanto, que além das categorizações gerais realizadas por cada instituição, os serviços educativos também possuem categorias complementares, estabelecidas a partir do público-alvo de cada tipologia de atividade educativa oferecida. No MAST, a Coordenação de Educação em Ciências (CED), responsável pelas ações educacionais da instituição, dentro do âmbito "público escolar", particulariza as categorias específicas "professores" e "alunos da licenciatura". Outras categorias são "estagiários", "bolsistas" e "público de baixa renda".

Na Pinacoteca, o Programa de Ação Educativa também trabalha com categorias de públicos específicas relacionadas aos programas desenvolvidos. Dessa forma, existe o público "educadores", composto pelos professores e educadores participantes dos cursos de formação. Existe o "público com necessidades especiais" e, também, o público denominado "grupos em situação de vulnerabilidade social". Além desses, existe o "público de visitação espontânea" e o "público de funcionários".

O Serviço Técnico de Musealização do MAE, responsável pelas ações educativas do Museu, categoriza seus públicos entre "público escolar" e "público não escolar", conforme o tipo de atividade oferecida. Dentro do público escolar, existem ações específicas para os "professores" e ações para os "grupos escolares". Já, na categoria público não escolar, existe o "público de terceira idade" e o "público de baixa renda". Também existe o público "estagiários" e o "público com necessidades especiais".

O que se percebe é uma demarcação tipológica de público que leva em consideração os mais diferentes critérios. O critério do contexto social da visita categoriza o público escolar e o público espontâneo. Segue o critério de faixas etárias, que engloba o público de terceira idade. Existe também o público categorizado por sua profissão/ocupação, como funcionários, estagiários, educadores e professores. Os demais públicos são agregados a partir de suas características intrínsecas, como público de baixa renda ou em situação de vulnerabilidade social e público com necessidades especiais.

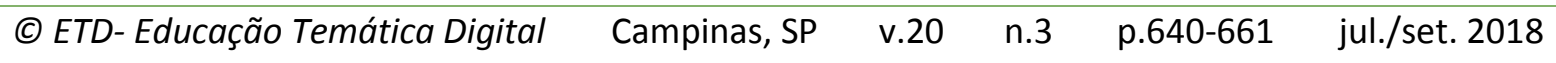


De acordo com a teorização proposta por Bernstein (1996), a seleção dos conteúdos e sua distribuição por idades são estabelecidas pelos princípios de classificação presentes no discurso instrucional específico. Isso quer dizer que a matriz temporal dos museus é determinada pelos princípios subjacentes ao discurso instrucional específico dessas instituições. Dessa forma, uma classificação temporal forte cria uma estratificação dos adquirentes/públicos por anos/faixas etárias. Já uma classificação temporal fraca cria estratos mistos em termos etários. Diferentemente do ambiente escolar, no qual os critérios temporais separam os adquirentes em turmas/séries divididas por faixas etárias, as atividades educativas do museu podem congregar diferentes perfis etários em uma mesma situação educacional. Esse é o caso, por exemplo, das visitas educativas para público espontâneo que podem reunir adultos e crianças.

A matriz temporal em Bernstein é implícita ao discurso pedagógico e, além de separar os adquirentes por faixas etárias, também regula a forma de comunicação entre adquirentes e transmissores, estabelecendo a sequência, o ritmo e os critérios de avaliação. Nos museus, são as avaliações que, em última instância, subsidiam os educadores nas tomadas de decisões sobre as atividades e as temáticas educacionais adotadas. Nesse sentido, é interessante perceber como o paradigma da avaliação de exposições e a pesquisa de público nos museus têm se deslocado de tendências mais quantitativas para o desenho de estudos mais antropológicos ou qualitativos (HOOPER-GREENHILL, 1994).

Essa nova tendência pode ser verificada no uso, por exemplo, da metodologia Generical Learning Outcomes (GLO) pela equipe do Programa de Inclusão Sociocultural (PISC) da Pinacoteca do Estado. Por ter sido criada especificamente para uso em espaços não formais de educação, especialmente museus, bibliotecas e arquivos, a metodologia amplia a noção de aprendizagem para além dos aprendizados conceituais. Para a utilização dos GLO em suas atividades, a equipe do PISC fez uma adaptação da metodologia, criando os seguintes indicadores: aquisição de conhecimento e compreensão relacionadas ao conhecimento formalizado; aquisição de habilidades; mudança de valores, atitudes e sentimentos; promoção de prazer, inspiração e criatividade; e mudança de comportamento.

Para nós, essas categorias têm servido bem de base de análise, porque concordamos que todas essas instâncias acontecem em uma visita ao museu. Tudo isso pode ser percebido por meio de avaliação e faz parte do aprendizado no museu. (PINA educador 2).

Realizada por meio de questionários com os públicos atendidos, observação e relatórios dos educadores, a avaliação por meio dos GLO traz elementos que auxiliam nas tomadas de decisão para a melhoria do programa, além de fornecer subsídios para a compreensão de como os públicos se relacionam com a instituição museal e suas atividades educacionais.

(C) ETD-Educação Temática Digital Campinas, SP $\quad$ v.20 $\quad$ n.3 $\quad$ p.640-661 jul./set. 2018


No caso do MAST, as avaliações estão relacionadas à compreensão da efetividade dos processos educacionais estabelecidos por meio de suas exposições e ações educacionais, bem como relacionadas às possibilidades de interação do público com essas ações.

Essa sala das "Estações"17, talvez não tenha havido aqui no museu uma outra exposição que tenha sido mais formalmente avaliada. E esses resultados, essas pesquisas, apontam modificações que devem ser feitas. Então, nessa atual versão, a gente mudou muita coisa, pautados no resultado das pesquisas. A gente vai até o público, a gente estuda o público interagindo com os aparatos, com a exposição, observa, as pessoas respondem questionário, as pessoas são entrevistadas $e$, no final, a gente tem um quadro; olha isso é bom, mas tem esse problema, tem esse, tem aquele outro; então, troca isso, fecha. (MAST - educador 1).

Inseridas dentro da lógica de produção científica estabelecida pela equipe de educadores do MAST, parte das avaliações realizadas está coadunada com os questionamentos pertinentes à área de educação em ciências.

Se você for ver historicamente como as concepções educativas do museu foram se apresentando, você vai ver que elas sempre estão atreladas aquilo que a pesquisa mostra como o interessante, o caminho a ser buscado. (MAST-educador 1).

Além das avaliações relacionadas com as linhas de pesquisa institucionais, existem também, no MAST, as avaliações formativas, que buscam estabelecer melhorias e ajustes nos processos educacionais em curso. Algumas dessas avaliações são levadas de forma sistemática - com elaboração de objetivos, instrumentos de coleta de dados e análises posteriores - e outras são realizadas por meio de reuniões de acompanhamento da própria equipe de educação.

Essa dinâmica, pautada na percepção dos próprios educadores sobre o funcionamento das ações, é utilizada também no MAE-USP. Nessa instituição, o setor educativo não realiza avaliações com coleta e análise de dados sistemáticos. De acordo com a coordenação da Divisão de Difusão Cultural, responsável pelo setor educativo, esse tipo de processo ainda não entrou na rotina educacional de forma sistematizada. Apesar de ser considerada importante, e de vários dados terem sido coletados ao longo dos anos, a tabulação ainda não foi realizada. De acordo com uma das educadoras, essa questão se deve também à ausência de uma equipe com maior número de pessoas e/ou de um profissional externo para a realização desse tipo de atividade.

O que se percebe, a partir do contexto apresentado, é que as avaliações e as investigações no MAST, assim como na Pinacoteca e no MAE-USP, não acontecem de forma sistemática em todas as ações educacionais realizadas. A lógica, nesse sentido, não se baseia

\footnotetext{
${ }^{17}$ Essa fala se refere à exposição "As estações do ano: a terra em movimento", do Museu de Astronomia e Ciências Afins.
}

(C) ETD-Educação Temática Digital Campinas, SP $\quad$ v.20 $\quad$ n.3 $\quad$ p.640-661 jul./set. 2018


na avaliação do adquirente/público que irá, a partir de sua performance, ser elevado de gradação - como pode ocorrer no ambiente escolar. A lógica da avaliação nos museus, quando estabelecida, está voltada à compreensão dos mecanismos atuantes na comunicação e na educação museal e na melhoria desses processos, seja de forma imediata, seja na construção de um marco referencial para a área.

Se percebe, nos museus estudados, a presença de um forte discurso de adaptabilidade às necessidades do público que, conclui-se, exerce um poder "regulador" sobre o discurso pedagógico dos museus. Essa regulação exercida pelo público é depreendida por meio das avaliações que, como foi visto, trazem, na atualidade, elementos para a compreensão de quem é esse público e de quais são suas necessidades. Essa regulação não quer dizer, entretanto, que não existam pressupostos do que uma ação educacional deva ser e sobre que assuntos deva tratar. Pelo contrário, os educadores têm objetivos explícitos sobre quais os efeitos que a ação educacional dos museus deve proporcionar em cada tipologia de público (MARTINS, 2015).

Esses objetivos são regulados pela matriz temporal que conforma o discurso instrucional e o discurso regulador, configurando-se como o "regulador crucial de controle sobre a comunicação na relação pedagógica" (DOMINGOS et al., 1986, p. 308). Frente à diversidade etária, e tipológica, dos públicos frequentadores dos museus, são estabelecidas ações educacionais com diferentes temporalidades. Ou seja, essa matriz provê um tempo fragmentado - distinto para cada tipologia de ação - estabelecido tanto a partir daquilo que os educadores julgam apropriado às ações educacionais museais, quanto a partir da diversidade de seus públicos.

Se, no ambiente escolar, a matriz temporal regula a separação dos adquirentes em faixas etárias, organizando as atividades em períodos fixos de tempo, na sala de aula e fora dela; no museu, é a variedade de públicos que frequenta a instituição que determina a diversidade temporal das atividades. É no "balanço" entre necessidades e características dos públicos, por um lado, e objetivos educacionais, derivados de diferentes tendências pedagógicas, por outro, que se estabelecem as formas de comunicação na relação pedagógica entre adquirentes/públicos e transmissores/educadores nos museus.

Outro aspecto da temporalidade nos museus é estabelecido a partir de sua não obrigatoriedade; ou seja, no museu, os adquirentes/públicos permanecem quanto tempo desejarem, na medida em que não existe uma avaliação coercitiva que os obrigue a cumprir determinadas tarefas visando algum tipo de compensação.

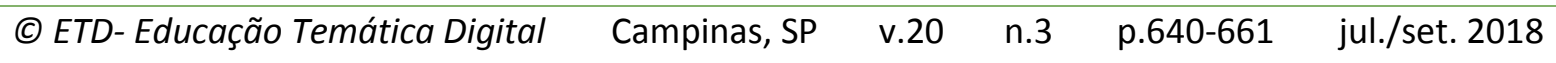




\section{CONCLUSÕES}

O objetivo desse artigo voltou-se à compreensão de aspectos da educação museal, com vistas a depreender a existência de um currículo nessa modalidade educacional. Sendo uma categoria analítica eminentemente escolar, seria possível a existência de um currículo da educação museal? Para isso, foram discutidos autores da área que se debruçam sobre as teorias curriculares, trazendo elementos importantes para a percepção de como essa educação se constitui. Entretanto, suas contribuições, apesar de importantes na demarcação da utilização do conceito de currículo para a compreensão da educação museal, não apontavam aspectos mais processuais de sua constituição. Dessa forma, optou-se pela utilização do conceito de dispositivo pedagógico de Basil Bernstein, permitindo um recorte processual sobre essa modalidade educacional. $\mathrm{O}$ currículo da educação museal foi, dessa forma, compreendido não por meio de seus resultados ou práticas específicas, mas como parte de um processo no qual participam, de forma assimétrica, educadores de museus e público.

Nesse sentido, o discurso pedagógico dos museus foi analisado a partir da categoria de tempo. Dentro da teorização de Bernstein, o tempo é o elemento que regula a comunicação pedagógica no interior do dispositivo. A diversidade de públicos atendidos pelos serviços educativos é um dos aspectos característicos dos museus. Neles, existem diferentes tempos - cada um adaptado às necessidades de um público específico. Essa tipologia não é marcada pela seriação etária, como acontece no ambiente escolar, mas pelas características intrínsecas de cada público. Essas características são determinadas em função do contexto social da visita - no caso, por exemplo, do público escolar - ou do perfil socioeconômico - no caso, por exemplo, de pessoas em situação de vulnerabilidade social. Ou seja, a tipologização dos públicos é uma forma de controlar o processo educacional: tempo, conteúdo e metodologia são adaptados em função daquilo que é considerado, pelos educadores, como mais adequado para aquele público específico.

Esse controle, entretanto, é subvertido pela própria lógica temporal da visita ao museu. Inserida dentro da perspectiva do lazer educacional, a visita espontânea ao museu não tem $\mathrm{o}$ caráter de comparecimento obrigatório ${ }^{18}$. Outro aspecto importante do funcionamento da matriz temporal nos museus é o fato de as diferentes faixas etárias poderem ser reunidas em uma mesma atividade.

O funcionamento da matriz temporal dentro do dispositivo pedagógico de Bernstein também regula os critérios de avaliação. É por meio desses critérios que são estabelecidas,

\footnotetext{
${ }^{18}$ É somente no caso da visita e do público escolar que a questão da "obrigatoriedade" vai permear a ação educacional museal. Isso porque a lógica de funcionamento da escola é regulada por parâmetros que não são abandonados em outros ambientes educacionais (FREIRE, 1992).
}

$\begin{array}{llllll}\text { (c) ETD-Educação Temática Digital } & \text { Campinas, SP } & \text { v.20 } & \text { n.3 } & \text { p.640-661 } & \text { jul./set. } 2018\end{array}$


em última instância, as formas de comunicação entre adquirentes e transmissores. Nos três museus em foco, não existem estudos sistemáticos de público em todas as ações educacionais empreendidas. Em todos os casos, mesmo quando são realizadas pesquisas de público, são também empregados critérios mais subjetivos, baseados na percepção dos educadores, para a avaliação das atividades. Essa percepção dos educadores é, assim como as avaliações sistemáticas, utilizada para a remodelação das ações em função da efetividade no cumprimento de seus objetivos pedagógicos junto ao público.

O que se depreende é que a avaliação/estudo de público nos museus tem como meta a compreensão dos mecanismos atuantes na comunicação e na educação museal visando a melhoria desses processos. Ressalta-se aí a diferença do funcionamento da matriz temporal no ambiente escolar que, no geral, ao estabelecer a seriação etária dos adquirentes/estudantes, estabelece critérios de avaliação que implicam na evolução ou na reprovação para outro nível de ensino, com profundas consequências na vida dos sujeitos.

A relação entre conhecimento específico/acervo do museu, tempo e metodologia eixos estruturantes das ações educacionais existente nos museus - é regulada, portanto, pelos públicos, por um lado, e pelos objetivos educacionais dos educadores, por outro. Percebe-se, portanto, que é no "balanço" entre necessidades e características dos públicos, por um lado, e objetivos educacionais, por outro, que se estabelecem as formas de comunicação na relação pedagógica entre adquirentes/públicos e transmissores/educadores nos museus.

Os aspectos mencionados evidenciam os processos sociais em curso na constituição do currículo da educação em museus. Processos esses nos quais as instituições museais se encontram inseridas e que determinam um funcionamento específico para essa educação.

\section{REFERÊNCIAS ${ }^{i}$}

ALLARD, Michel; LEFEBVRE, Bernard. (Ed.). Le musée, un lieu éducatif. Montréal: Musée d'Art Contemporain de Montréal, 1997.

APPLE, Michel W. Ideologia e currículo. Porto Alegre: Artmed, 2006.

APPLE, Michel W. Repensando ideologia e currículo. In: MOREIRA, Antonio Flávio (Org.); SILVA, Tomaz Tadeu (Org.). Currículo, cultura e sociedade. São Paulo: Cortez, p. 39-58, 1995.

BEER, Valorie; MARSH, David D. A non-school curriculum model illustrated in a museum setting. Journal of Curriculum and Supervision. v.3, n.3, p. 221-239, 1998.

BERNSTEIN, Basil. A estruturação do discurso pedagógico. Classe, códigos e controle. Petrópolis: Vozes, 1996.

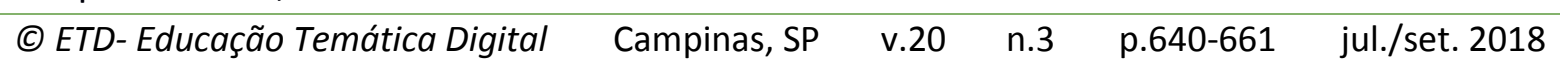


BERNSTEIN, Basil. Pedagogía, control simbólico e identidad. Madrid: Morata, Paideia, 1998.

BOGDAN, Robert; BIKLEN, Sari. Investigação qualitativa em educação. Porto: Porto, 1994.

COHEN, Louis; MANION, Lawrence; MORRISON, Keith. Research methods in education. New York: Routledge, 2007.

DOMINGOS, Ana M. et al. A teoria de Bernstein em sociologia da educação. Lisboa: Fundação Calouste Gulbenkian, 1986.

FORQUIN, Jean-Claude. Escola e cultura. As bases sociais e epistemológicas do conhecimento escolar. Porto Alegre: Artes Médicas, 1993.

FREIRE, Beatriz M. O encontro museu/Escola: o que se diz e o que se faz. Rio de Janeiro. 1992. Dissertação (Mestrado) - Departamento de Educação da Pontifícia Universidade Católica, 1992.

GOODLAD, John I.; KLEIN, M. Frances.; TYE, Kenneth A. Curriculum inquiry. New York: McGraw-Hill, 1979.

HEIN, George. Learning in the museums. London: Routledge, 1998.

HOOPER-GREENHILL, Eilean. Education, communication and interpretation: towards a critical pedagogy in museums. In: The educational role of the museum. London: Routledge, 1994, p. 3-25.

LIBÂNEO, José Carlos. Didática. São Paulo: Cortez, 1990.

LOPES, Alice C. e MACEDO, Elizabeth. O pensamento curricular no Brasil. In: LOPES, A. C. e MACEDO, E. (orgs.) Currículo: debates contemporâneos. São Paulo: Cortez, 2002, p. 13-54.

LOPES, Alice C. e MACEDO, Elizabeth. Teorias de currículo. São Paulo: Cortez, 2011.

MARTINS, Luciana Conrado. A constituição da educação em museus: o funcionamento do dispositivo pedagógico museal por meio de um estudo comparativo entre museus de artes plásticas, ciências humanas e ciência e tecnologia. 2011. Tese (Doutorado) - Faculdade de Educação, Universidade de São Paulo, São Paulo, 2011.

MARTINS, Luciana Conrado. Como é criado o discurso pedagógico dos museus? Fatores de influência e limites para a educação museal. Museologia \& Interdisciplinaridade. v. 1 II, $\mathrm{n}^{\circ}$. 6, mar. /abr., 2015, p. 14-20.

MARTINS, Luciana Conrado; MARANDINO, Martha. Políticas de financiamento da educação em museus: a constituição das ações educacionais em museus de artes plásticas, ciências humanas e ciência e tecnologia. Ensino Em Re-Vista, v.20, n.1, p.57-68, jan./jun. 2013 
MARANDINO, M. O conhecimento biológico nos museus de ciências: análise do processo de construção do discurso expositivo. 2001. Tese (Doutorado) - Faculdade de Educação, Universidade de São Paulo, São Paulo, 2001.

MOREIRA, Antonio Flávio.; SILVA, Tomaz Tadeu. Sociologia e teoria crítica do currículo: uma introdução. In: MOREIRA, Antonio Flávio (Org.); SILVA, Tomaz Tadeu (Org.). Currículo, cultura e sociedade. São Paulo: Cortez, 1995.

OLIVEIRA, Adriano Dias. Biodiversidade e museus de ciências: um estudo sobre transposição museográfica nos dioramas. 2010. Dissertação (Mestrado) - Interunidade em Ensino de Ciências, Universidade de São Paulo, São Paulo, 2010.

ROBERTS, Lisa C. From knowledge to narrative: educators and the changing museum. Washington, London: Smithsonian Institution, 1997.

ROSE, Julia. Expanding conversations. How curriculum theory can inform museum education practice, Journal of Museum Education, v. 31, n. 2, 2006, p.75-76.

SADOVNIK, Alan R. Basil Bernstein's theory of pedagogic practice. In: SADOVNIK, Alan R. (Org.) Knowledge and pedagogy: the sociology of Basil Bernstein. Norwood: Ablex Publishing Corporation, p.3-35, 1995.

SCHWAB, Joseph J. The practical 3: translation of curriculum. In: School Review 81, n.4, 1973, p.501-522.

SCHWAB, Joseph J. The practical 4: something for curriculum professors to do. In: Curriculum Inquiry 13, n.3, 1983, p. 239-265.

SEIBEL-MACHADO, Maria Iloni. O papel do setor educativo nos museus: análise da literatura (1987 a 2006) e a experiência do Museu da Vida. Campinas, 2009. Tese (Doutorado) - Instituto de Geociências, Universidade Estadual de Campinas, 2009.

SILVA, Tomaz Tadeu. 0 currículo como fetiche: a poética e a política do texto curricular. Belo Horizonte: Autêntica, 1999.

SILVA, Tomaz Tadeu. Documentos de identidade: uma introdução às teorias do currículo. Belo Horizonte: Autêntica, 2002.

SOUZA, Maria P. C. O discurso sobre Biodiversidade e Conservação em exposições de imersão. 2017. Tese (Doutorado) - Faculdade de Educação, Universidade de São Paulo, São Paulo, 2017.

SOREN, Barbara. The museum as curricular site. Journal of Aesthetic Education, v.26, n.3, 1992, p. 91-101.

VALLANCE, Elizabeth. The public curriculum of orderly images. In: Educational Researcher, v. 24, n. 2, 1995, p. 4-13.

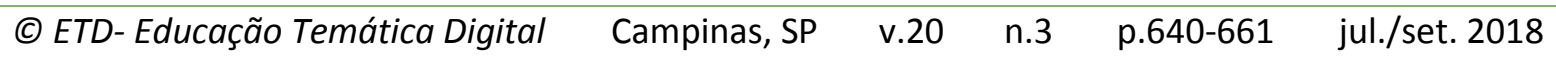


VALLANCE, Elizabeth. Museum education as curriculum: four models, leading to a fifth. In: Studies in Art Education, v.45, n.4, 2004, p. 343-358.

VALLANCE, Elizabeth. Finding order : curriculum theory and the qualities of museum education. In: Journal of Museum Education, v.31, n.2, 2006, p. 133-142.

VALENTE, Maria Ester Alvarez. Museus de Ciências e Tecnologia no Brasil: uma história da museologia entre as décadas de 1950-1970. Campinas, 2008. Tese (Doutorado) - Instituto de Geociências, Universidade Estadual de Campinas, 2008.

\footnotetext{
${ }^{\mathrm{i}}$ Revisão gramatical sob a responsabilidade de: Jorge Alves de Lima Bacharel e Licenciado em Língua Portuguesa (FFLCH/USP).

E-mail: joralima@gmail.com
} 